\title{
The prevalence of hyperglycemia in neonatal hypernatremic dehydration (NHD) and its correlation with prognosis in exclusively breastfed infants: A cohort study
}

\author{
Prevalencia de hiperglucemia en la deshidratación \\ hipernatrémica neonatal y su correlación con el pronóstico
}

Hassan Boskabadi, ${ }^{1}$ Maryam Zakerihamidi ${ }^{2}$

\begin{abstract}
BACKGROUND: Glucose changes are unknown in neonatal dehydration with hypernatremia.

OBJECTIVE: Was to investigate glucose status in neonatal hypernatremic dehydration (NHD) and its correlation with NHD prognosis.

MATERIAL AND METHODS: In this cohort study, serum glucose of 172 neonatal hypernatremic dehydration infants admitted to the Ghaem Hospital in Mashhad, Iran, was reviewed within the time frame of 2012 to 2017. The data were collected utilizing a questionnaire designed by the researchers to describe the characteristics of the mothers and neonates, as well as their laboratory and imaging study results. The neonatal hypernatremic dehydration infants were followed using the Denver Developmental Test II (DDT II) questionnaire at follow-up months 6, 12, 18, 24, 30, and 36.

RESULTS: 134 infants (77.91\%) had normal blood glucose levels and 38 infants (22.09\%) had a hyperglycemic status. In both groups, the differences in infant age $(p=0.000)$ weight upon admission $(p=0.035)$, breastfeeding duration $(p=0.003)$, frequency of urination $(p=0.001)$, blood sugar $(p=0.000)$, sodium $(p=0.008)$, urea $(p=0.000)$, creatinine $(p=0.000)$, and $\mathrm{pH}$ upon admission $(p=0.002)$ were statistically significant. Developmental delays were higher in the neonatal hypernatremic dehydration group with hyperglycemia $(p=0.029)$. There was a significant correlation between sodium levels and blood sugar $(p=0.000)$.

CONCLUSION: According to our study results, hyperglycemic neonatal hypernatremic dehydration infants had an older referral age; higher sodium, urea, and creatinine levels; lower weight upon admission; shorter breastfeeding duration; lower frequency of urination; and lower blood $\mathrm{pH}$. Therefore, checking the blood sugar of infants with hypernatremia is recommended and high serum glucose is a poor prognosis criterion in infants with neonatal hypernatremic dehydration.

KEYWORDS: Neonates; Hyperglycemia; Hypernatremia; Hypernatremic dehydration; Prognosis; Developmental delay

Resumen

ANTECEDENTES: Se desconocen los cambios en la glucosa de los neonatos con deshidratación hipernatrémica.

OBJETVO: Investigar el estado de la glucosa en la deshidratación hipernatrémica neonatal y su correlación con el pronóstico de quienes la padecen.

MATERIALES Y MÉTODOS: Estudio de cohorte en el que se analizó la glucosa en suero de recién nacidos con deshidratación hipernatrémica neonatal en el Ghaem Hospital de Mashhad, Irán, entre los años 2012 y 2018. Los datos se recopilaron mediante la aplicación de un cuestionario elaborado por el investigador. El seguimiento de los infantes con deshidratación hipernatrémica se hizo con el cuestionario Denver Developmental Test II (DDT II) a los 6, 12, 18, 24, 30 y 36 meses.

RESULTADOS: Se estudiaron 172 pacientes: 134 (77.9\%) con glucemia normal y 38 $(22.09 \%)$ con hiperglucemia. En ambos grupos la edad del lactante $(p=0.000)$, peso al ingreso $(p=0.035)$, duración de la lactancia $(p=0.003)$, frecuencia de micción ( $p$
\end{abstract}

\begin{abstract}
${ }^{1}$ Professor, Department of Pediatrics, Faculty of Medicine, Faculty Member of School of Medicine, Mashhad University of Medical Sciences, Mashhad, Iran Orcid ID: $\underline{0000-0003-4022-5426}$

${ }^{2}$ Assistant professor, $\mathrm{PhD}$ in reproductive health, Department of Midwifery, Tonekabon Branch, Islamic Azad University, Tonekabon, Iran.

Orcid ID: 0000-0002-6543-9095
\end{abstract}

Received: 21 February 2019

Accepted: 30 October 2020

Correspondence

Maryam Zakerihamidi

maryamzakerihamidi@yahoo.co.nz

This article should be cited as Boskabadi H, Zakerihamidi M. The prevalence of hyperglycemia in neonatal hypernatremic dehydration (NHD) and its correlation with prognosis in exclusively breastfed infants: A cohort study. Acta Pediatr Méx 2020; 249-56. 


\section{INTRODUCTION}

It is common for infants to lose some weight during the first days of life and it is usually regained by the end of the first week. If weight loss continues after the first week or there was rapid loss during the first days (more frequent than $2 \%$ of body weight per day), the family and physician should be concerned about low breast milk supply. If the problem is not corrected, neonatal hypernatremic dehydration (NHD) can occur. Approximately $1.6 \%-2.5 \%$ of infants admitted to the hospital present with NHD. ${ }^{1-3}$ Clinical symptoms of the condition include restlessness, irritability, lethargy, seizure, jaundice, poor breastfeeding, crying, and hyperthermia. ${ }^{4}$ Due to the gradual occurrence of dehydration and hypernatremia, diagnosis of NHD is difficult and dehydration is often not recognized. Thus, infants with hypernatremic dehydration may not see a doctor until there are complications of reduced urination, lethargy, weakness, neurologic symptoms, thrombosis, or seizure. $5,6,7$

Other complications of hypernatremia can be hyperglycemia, hypokalemia, and renal tubular damage. ${ }^{2}$ Hypernatremia results in endocrine dysfunction. Available evidence shows that hypernatremia and hyperosmolarity are related to impaired glucose metabolism by insulin and impaired glucose release by glucagon. ${ }^{3}$ Hyper- glycemia increases serum osmolality, causing water to move out of the cells, consequently reducing the serum sodium level. ${ }^{4}$ Sodium loss occurs due to osmotic diuresis and the lack of insulin required for sodium absorption in the renal distal tubules. Hypernatremia may occur when water loss is greater than sodium loss. In the absence of insulin, glucose is bound to the extracellular fluid and the liquid flows due to the osmotic activity of glucose from the intracellular to the extracellular space, and in turn, the intracellular sodium concentration is reduced. ${ }^{5}$ Nevertheless, the mechanism of the simultaneous correlation between hyperglycemia and hypernatremia is not well understood.

The incidence of NHD is increasing in Iran, and parents, physicians, and healthcare workers are not aware of the importance of early detection and control, through rapid, accurate treatment. ${ }^{6}$ Long-term complications including developmental delay and mortality in neonates with hypernatremic dehydration underline the need for proper care of newborns in the first weeks of life. Recognition of predisposing factors of poor prognosis in those infants may lead to more accurate control of risk factors and reduce said problems. The role of serum sodium in neonatal complications has been evaluated in different studies, but with less focus on other laboratory test results in those infants and their correla- 
tion with future outcomes. Thus, the present cohort study aimed to evaluate glucose status in neonates with hypernatremic dehydration and compare the prognosis of NHD, based on the blood glucose status.

\section{PATIENTS AND METHODS}

We evaluated the effects of serum glucose status in neonates with hypernatremic dehydration in a cohort study and compared their prognoses, based on blood glucose status. The neonates with hypernatremic dehydration were divided into two groups: infants with normoglycemic status and infants with hyperglycemic status. The infant hyperglycemia criterion was serum glucose level higher than $180 \mathrm{mg} / \mathrm{dL}$. Neonates with congenital abnormality, prematurity, severe hyperbilirubinemia (serum bilirubinemia $>20$ $\mathrm{mg} / \mathrm{dL}$ ), and nonexclusive breastfeeding were excluded from the analysis.

The present study was conducted on 172 hospitalized neonates with NHD (serum sodium > $150 \mathrm{mg} / \mathrm{dL}$ ) at the Ghaem Educational Hospital of Mashhad, within the time frame of 2012 to 2017, using available sampling methods. The data were collected through a questionnaire designed by the researchers to describe the maternal characteristics (mode of delivery, breast problems), neonatal characteristics (blood sugar, age, duration of hospitalization, birth weight, weight upon admission, Apgar score, the time interval for the first breastfeeding after birth, frequency of breastfeeding, frequency of urination, bowel movement frequency, the time interval for the first bowel movement after birth, duration of feeding, sex, parental concerns, letdown reflex, complications of treatment, and prognosis), laboratory tests (sodium, potassium, urea, creatinine, bilirubin, hematocrit, platelets, $\mathrm{pH}$, and glucose) and imaging studies (brain CT scan, kidney ultrasound). Glucose was tested by oxidase and the Pars Azmon kit and sodium and potassium were tested by ionogram. All clinical and diagnostic examinations of the infants were conducted by a neonatologist.

The infants were compared, based on blood sugar status. The neonates with hypernatremic dehydration were then followed, using the Denver Developmental Test II questionnaire at follow-up months 6, 12, 18, 24, 30, and 36. The Denver Developmental Screening Test II is an international test for evaluating the growth and development of children from birth to 6 years of age and assesses children in the following 4 areas: 1 ) personal-social contacts, 2) fine motor functions, 3) language (speaking), and 4) gross motor functions. Topics in the Denver II have been carefully selected in terms of reliability and integrity of norms in all subgroups and cultures. Developmental delay was considered when there was a problem in any of the four fields (i.e., one of the four categories [gross motor function, fine motor function, personal-social contacts, or speaking]). ${ }^{7,8}$

After review and follow-up of those children at age three, they were divided into two groups: natural outcomes (normal development at age three) and abnormal outcomes (developmental delay or death), after which the serum glucose levels of those infants upon admission were compared.

The present study was approved by the Ethics Committee of the Research Department of the Mashhad University of Medical Sciences (code 951325, IR.MUMS.fm.REC.1396.112) and the parents of the infants gave their informed consent, before entering the study.

Statistical Analysis: SPSS software version 20 was utilized for the data analysis. In addition to the use of tables and statistical charts, we discussed the 
results and compared the two groups of neonates with hypernatremic dehydration (those with normoglycemic status and those with hyperglycemia status), using the chi-square test and the t test. The predictive factors for hypernatremic dehydration, based on serum sodium level and blood glucose, were determined utilizing the ROC curve. A p value $<0.05$ was considered statistically significant.

\section{RESULTS}

Of the 172 infants that presented with NHD, 134 cases (77.91) had normoglycemic status and 38 cases (22.09) had hyperglycemic status. According to the study results, the average age of infants upon admission was 8.07 days \pm 2.85 in the group of normoglycemic neonates and 11.36 days \pm 2.81 in the group of hyperglycemic neonates ( $p$ $=0.000$ ). The average birth weight of infants was $3202.82 \mathrm{~g} \pm 510.97$ in the normoglycemic group and $3327.63 \mathrm{~g}$ days \pm 545.46 in the hyperglycemic group $(p=0.192)$. The average weight upon admission was $2752.83 \mathrm{~g} \pm 468.98$ in the normoglycemic group and $2575.00 \mathrm{~g} \pm 442.62$ in the hyperglycemia group $(p=0.035)$. Table 1 shows the other characteristics of the infants analyzed.

There were no significant differences between the two groups in relation to hospital stay $(\mathrm{p}=$ $0.532)$, Apgar score $(p=0.929)$, time interval for first breastfeeding after birth $(p=0.659)$, breastfeeding frequency $(p=0.112)$, bowel movement frequency $(p=0.765)$, time interval to first bowel movement after birth $(p=0.728)$, potassium ( $p$ $=0.460)$, bilirubin $(p=0.511)$, hematocrit $(p=$ $0.953)$, platelets $(p=0.531)$ and feeding duration ( $p=0.683$ ) (Table 1, $p>0.05)$. There was a significant difference between the two groups regarding neonate age $(p=0.000)$, weight upon admission ( $p=0.035)$, breastfeeding duration $(p=0.003)$, frequency of urination $(p=0.001)$, blood glucose $(p=0.000)$, sodium $(p=0.008)$, urea $(p=0.000)$, creatinine $(p=0.000)$ and $p H$ upon admission $(p=0.002)$ (Table 1, Figure 1).

Table 1. Comparison of variables in the neonates with normoglycemic hypernatremia and the neonates with hyperglycemic hypernatremia

\begin{tabular}{|c|c|c|c|}
\hline $\begin{array}{l}\text { Group } \\
\text { variables }\end{array}$ & $\begin{array}{l}\text { Normoglycemic status of } 134 \\
\text { infants (77.91) }\end{array}$ & $\begin{array}{l}\text { Hyperglycemic status } \\
\text { of } 38 \text { infants }(22.09)\end{array}$ & $\begin{array}{c}\text { Significance level * } \\
\text { (t test) }\end{array}$ \\
\hline Blood glucose (mg/dL) & $84.08 \pm 31.15$ & $342.34 \pm 102.51$ & 0.000 \\
\hline Age upon admission (days) & $8.07 \pm 4.85$ & $11.36 \pm 2.81$ & 0.000 \\
\hline Length of hospital stay (days) & $5.12 \pm 2.09$ & $6.33 \pm 2.30$ & 0.532 \\
\hline Birth weight $(\mathrm{g})$ & $3202.82 \pm 510.97$ & $3227.63 \pm 545.46$ & 0.192 \\
\hline Weight upon admission (g) & $2752.83 \pm 468.98$ & $2575.00 \pm 442.62$ & 0.035 \\
\hline Apgar score & $8.95 \pm 0.52$ & $8.94 \pm 0.65$ & 0.929 \\
\hline $\begin{array}{l}\text { Time interval for the first breastfeeding } \\
\text { after birth (hour) }\end{array}$ & $2.73 \pm 0.61$ & $2.97 \pm 0.92$ & 0.659 \\
\hline Breastfeeding frequency & $7.38 \pm 2.54$ & $6.65 \pm 2.25$ & 0.112 \\
\hline Breastfeeding duration (minutes) & $17.98 \pm 9.57$ & $12.76 \pm 8.93$ & 0.003 \\
\hline Frequency of urination & $3.64 \pm 1.69$ & $2.86 \pm 1.04$ & 0.001 \\
\hline Bowel movement frequency & $3.05 \pm 0.19$ & $3.17 \pm 0.93$ & 0.765 \\
\hline $\begin{array}{l}\text { Time interval for the first bowel } \\
\text { movement after birth (hour) }\end{array}$ & $12.19 \pm 8.34$ & $13.20 \pm 7.04$ & 0.728 \\
\hline
\end{tabular}

*Values are based on mean \pm standard deviation. 


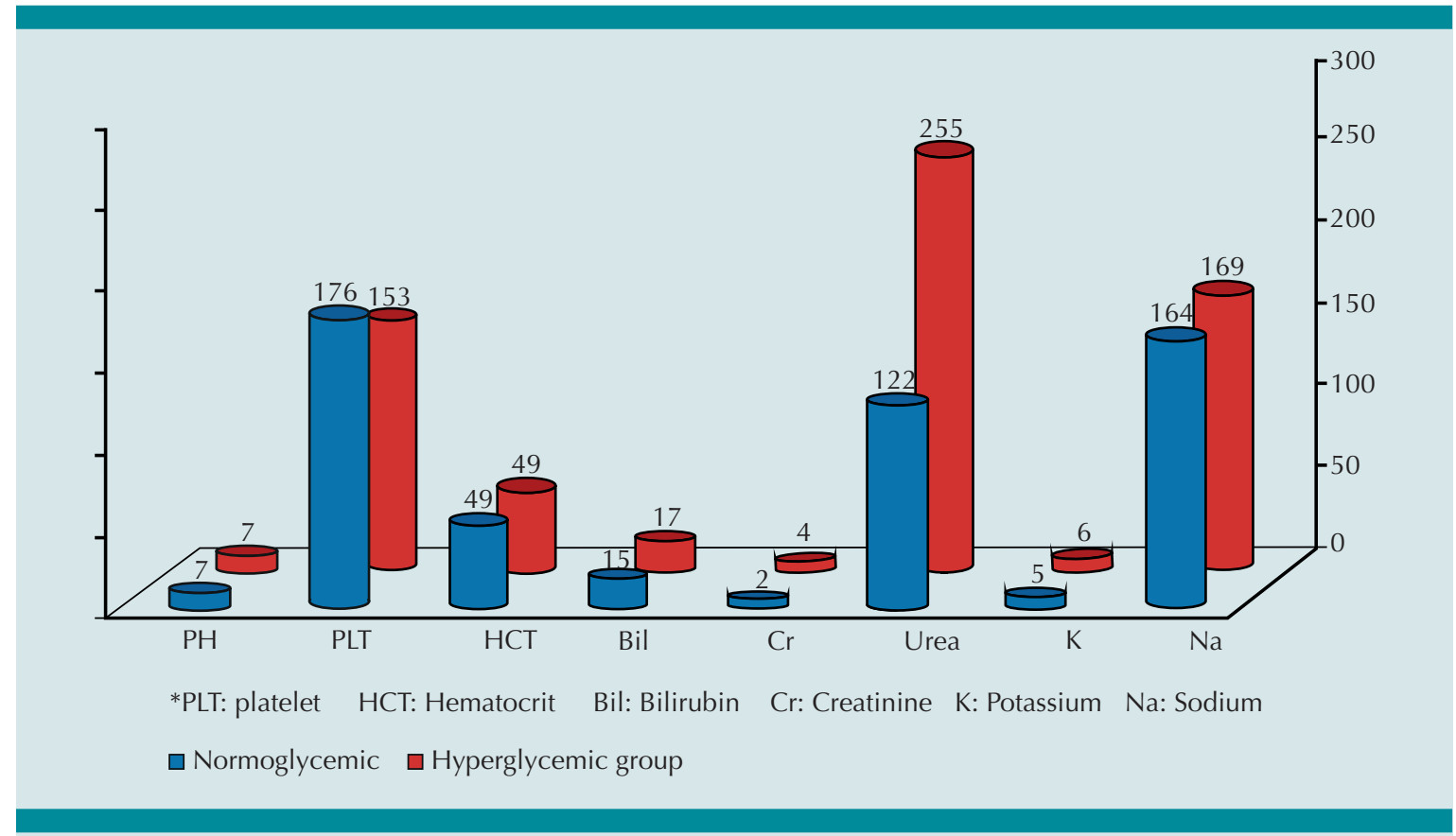

Figure 1. Mean comparison of the laboratory parameters in neonates with normoglycemic hypernatremia and neonates with hyperglycemic hypernatremia.

Ninety-three infants (58.9\%) were males and 42 infants $(41.1 \%)$ were females. There were more males in the normoglycemic neonate group $(66.1 \%)$ and more females in the hyperglycemic neonate group $(67.6 \%)(p=0.000)$. Hyperthermia was the most common parental concern in the normoglycemic neonate group (23.2\%) and poor feeding was the most frequent parental concern in the hyperglycemic neonate group $(39.5 \%)(p=0.050)$. There were let-down reflex problems for the mothers of most of the hyperglycemic hypernatremic neonates $(71.1 \%)(p=$ 0.004). There was a higher rate of treatment side effects in the hyperglycemic hypernatremic neonates than in the normoglycemic hypernatremic neonates $(p=0.004)$. The most common side effect in the hyperglycemic hypernatremic neonate group was seizure (37.5\%). Renal ultrasound showed that abnormalities were higher in the hypernatremic infants with hyperglycemia $(p=$ 0.005) and the most common renal problem was kidney stones. Infant prognosis was significantly different between the two groups ( $p=0.029)$, i.e., developmental delay was higher in the hypernatremic neonate group with hyperglycemia. Developmental delays were higher in the NHD group with hyperglycemia ( $p=0.029)$ (Figure 2).

According to the study results, there was a statistically significant correlation between sodium levels and blood glucose concentration ( $\mathrm{p}=$ 0.000). The correlation was linear and direct, i.e., the glucose level increased when the sodium level increased in neonates with hypernatremia (Diagram 1).

\section{DISCUSSION}

According to the results of this study, the NHD hyperglycemic neonates presented with later severe weight loss and a lower frequency of urination. They also had histories of critical 


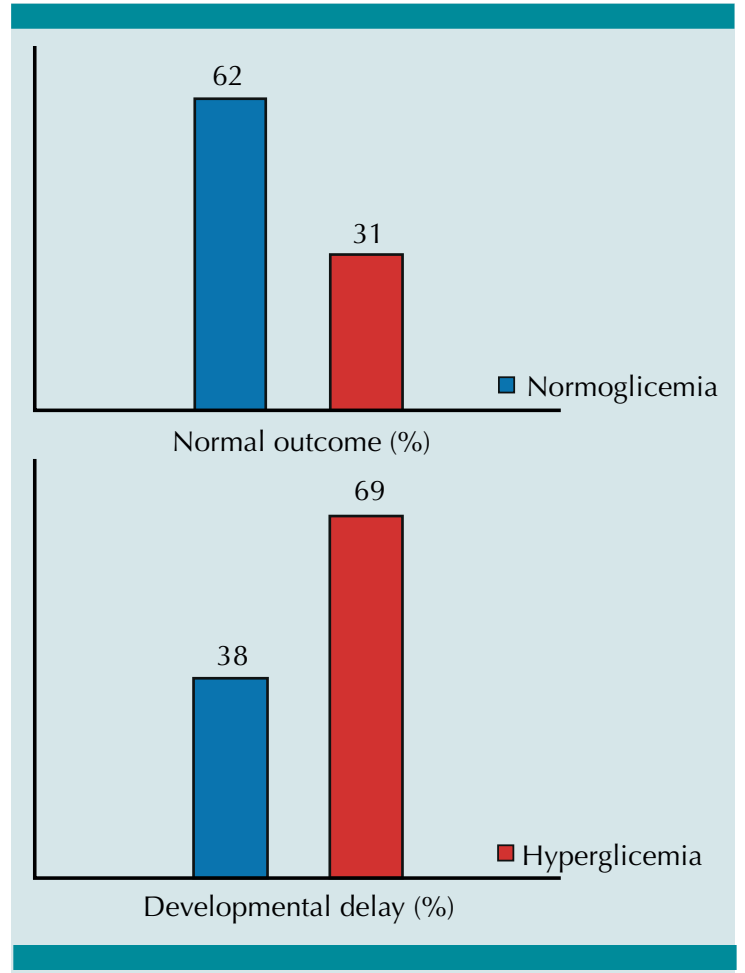

Figure 2. Comparison of the prognosis of neonates with normoglycemic hypernatremia and neonates with hyperglycemic hypernatremia.

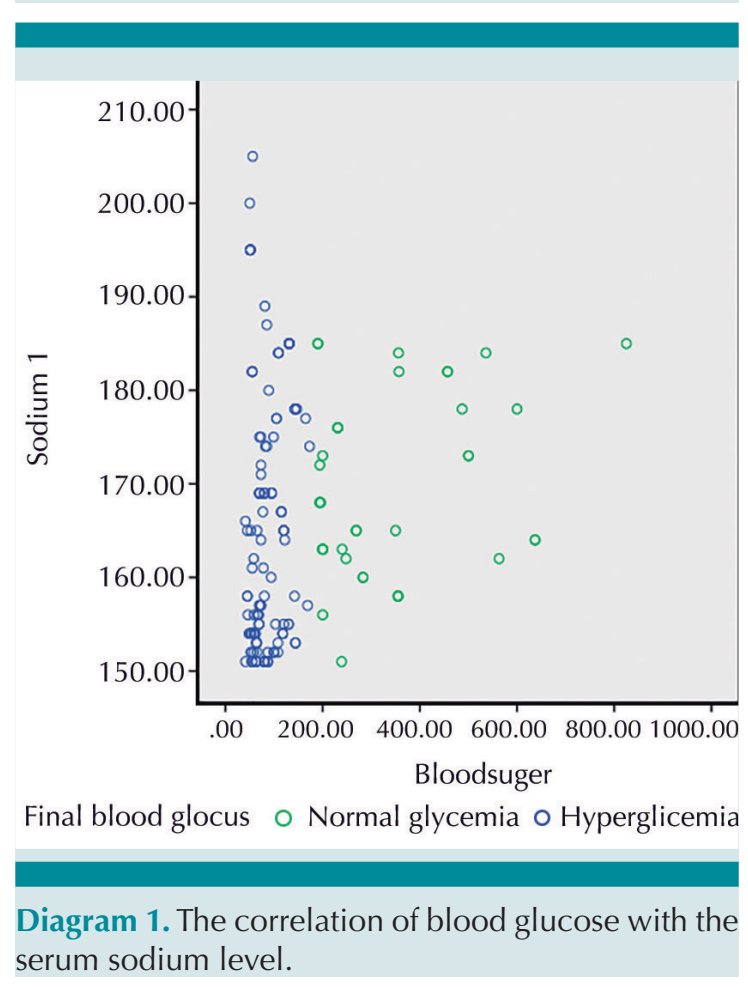

problems, such as acidosis, uremia, and hypernatremia. Unfortunately, the long-term prognosis of those neonates was even worse. A review of studies on blood glucose status in neonates with hypernatremia in Iran and other countries showed that ours is the only study that has compared normoglycemia status and hyperglycemia status in hypernatremic neonates. The innovation of the present study is the determination of health and prognosis status in hypernatremic neonates with different blood glucose statuses.

Approximately one-fifth of the hypernatremic infants had hyperglycemia. The increase of plasma sodium in the presence of hyperglycemia clinically indicates significant dehydration. ${ }^{9}$ In the study by Borna et al. (2014), there was no significant correlation between serum sodium and glucose levels. ${ }^{10}$ Hyperosmolarity causes broad changes in blood sugar levels, and even in CSF glucose levels, and can be produced by hypernatremic dehydration. ${ }^{11}$ Ghalehgolab et al. (2009) classified 300 term and preterm hospitalized infants into two groups: those with hypernatremia and those without hypernatremia. Nine percent of the infants had hypernatremia. There were no significant differences between blood glucose levels and hypernatremia in that study. ${ }^{12}$ In the Turkish study by Uras et al., there was an inverse relationship between serum sodium concentration and blood glucose in patients. ${ }^{13}$ However, the mechanism involved in the association of hyperglycemia with $\mathrm{NHD}$ is unclear, but the severity of hypernatremia appears to increase the possibility of the presence of hyperglycemia.

The rate of weight loss in hyperglycemic hypernatremic infants was higher than that of infants with normal blood sugar. Poor nutrition is the most important cause of NHD. Regular weight measurement is useful for assessing nutritional status. Weight loss above $10 \%$ of birth weight, or 
a lack of birth weight regain after the first week, is indicative of poor nutrition. ${ }^{14}$ Increased hypernatremia and jaundice have been shown to be related to the severity of weight loss. ${ }^{15}$ Infants with greater weight loss are more likely to present with hypernatremia and hyperglycemia. Therefore, weighing infants within the first 72 to 96 hours after birth should be taken into account for the prevention of hypernatremia and hyperglycemia.

The most common concern for the parents of normoglycemic infants $(23.2 \%)$ was hyperthermia and poor feeding was the most frequent concern for the parents of hyperglycemic infants (39.5\%). Hyperthermia is mainly due to dehydration and is rarely caused by infection. At present, hyperthermia occurs more commonly in infants whose mothers are discharged from the hospital fewer than 48 hours after giving birth. It is likely that those mothers have not had adequate information about breastfeeding, they present with low volumes of breast milk the first days after giving birth, and probably keep the infant overbundled. Dehydration in infants can be associated with hypernatremia, hyperglycemia, hypercalcemia, and indirect hyperbilirubinemia, which can have serious and persistent consequences for infants. ${ }^{16}$ Side effects of hypernatremic dehydration do not occur exclusively in stages of hypernatremia and dehydration, but also following treatment and rehydration. Severe treatment is as dangerous as delayed treatment or incomplete treatment, because a dramatic drop in serum sodium concentration leads to cerebral edema, seizure, and neurologic complications. ${ }^{17}$ Thus, hyperglycemia in NHD neonates raises the possibility of treatment complications, such as seizure. Intracranial hemorrhage has been reported in $15 \%$ of hypernatremic infants with normoglycemia and 20\% of hypernatremic infants with hyperglycemia. Hypernatremic dehydration usually presents together with hyperglycemia and hypokalemia, which can increase the risk of central nervous system complications..$^{18}$ In the study by Bermik et al. (2016), hyperglycemia increased the risk of intracranial hemorrhage in preterm infants with hypernatremia. ${ }^{19}$

Developmental delay was more frequent in the group of hypernatremic infants with hyperglycemia $(71.06 \%)$. Hypernatremia and hyperglycemia are common causes of hypertonicity. Hypertonicity caused by dehydration of different body organs leading to neurologic complications can be life-threatening. ${ }^{20}$ Glucose is an essential substance for normal brain function. Normal levels of blood glucose during the neonatal period ensure proper neural development. ${ }^{21}$ In their study, Moritz et al. showed that mortality was higher in the hypernatremic infants that were also hyperglycemic. ${ }^{22}$ However, the mechanism involved in the adverse effects of hypernatremia with hyperglycemia is unknown. Perhaps hyperglycemia is indicative of the intensity of stress and the severity of hypernatremia. Our study limitation was the failure to evaluate the amount of time it took to correct the hyperglycemia. Therefore, evaluating the duration of hyperglycemia as a variable in future studies is recommended.

\section{CONCLUSION}

Our study suggests that NHD neonates with hyperglycemia were older upon admission, had higher sodium, urea, and creatinine levels, and had lower weight upon admission, shorter breastfeeding duration, lower frequency of urination, and lower blood $\mathrm{pH}$. In addition, there were statistically significant differences between the two study groups regarding infant sex, parental concern upon admission, and the let-down reflex. Renal ultrasound showed that abnormalities were higher in the group of hypernatremic neonates 
with hyperglycemia. Developmental delays were also more frequent in the hypernatremic neonates with hyperglycemia (71.06\%). Hence, checking the blood sugar level of neonates with hypernatremia is recommended. In addition, high levels of serum glucose appear to be a criterion for poor prognosis in NHD neonates.

\section{Acknowledgment}

The present study was approved by the Mashhad University of Medical Sciences, code 951325, IR.MUMS.fm.REC.1396.112. The researchers wish to thank the Deputy of University Research, the Research Director, and other officials, as well as all those who helped us with this project.

\section{Author disclosure}

The authors declare that they have no potential conflicts of interest with respect to the research, authorship, and/or publication of this article.

\section{REFERENCES}

1. Caglar M, Özer I, Altugan F. Risk factors for excess weight loss and hypernatremia in exclusively breast-fed infants. Brazilian Journal of Medical and Biological Research. 2006; 39 (4): 539-44. https://doi.org/10.1590/S0100$879 \times 2006000400015$

2. Palevsky P, editor Hypernatremia. Seminars in Nephrology 1998.

3. Komjati $\mathrm{M}$, et al. Detrimental effect of hyperosmolality on insulin-stimulated glucose metabolism in adipose and muscle tissue in vitro. Biochemical Medicine and Metabolic Biology. 1988; 39 (3): 312-8. https://doi.org/10.1016/08854505(88)90091-6

4. Hillier TA, et al. Hyponatremia: evaluating the correction factor for hyperglycemia. The American Journal of Medicine. 1999; 106 (4): 399-403. 10.1016/s00029343(99)00055-8

5. Matz R. Management of the hyperosmolar hyperglycemic syndrome. American Family Physician. 1999; 60 (5): 1468-76.
6. Boskabadi H, Kalateh Molaee M. Survey of Clinical Evidence in Newborns with Hypernatremic Dehydration. Journal of Ardabil University of Medical Sciences. 2016; 15 (4): 441-50.

7. Frankenburg WK, et al. The Denver II: a major revision and restandardization of the Denver Developmental Screening Test. Pediatrics. 1992; 89 (1): 91-7.

8. Boskabadi $\mathrm{H}$, et al. Assessment of risk factors and prognosis in asphyxiated infants. Iranian Journal of Pediatrics. 2015; 25 (4). 10.5812/ijp.2006

9. Kitabchi $A E$, et al. Hyperglycemic crises in adult patients with diabetes. Diabetes care. 2009; 32 (7): 1335-43. https://doi. org/10.2337/dc09-9032

10. Borna $\mathrm{H}$, et al. The frequency of clinical and laboratory findings of hypernatremia and factors affecting its severity in term newborns. Tehran University Medical Journal. 2014; 72 (8): 546-54.

11. Gutberlt R, Santos A. Altered carbohydrate metabolism in sick premature. Pediatr Res. 1973; 7: 312-3.

12. Ghalehgolab Behbahan A, et al. Evaluation of dehydration and hypernatremia in neonates admitted to Tabriz Children's Hospital. Med J Tabriz Univ Med Sci. 2009; 31 (2): 83-7.

13. Uras $\mathrm{N}$, et al. Moderate hypernatremic dehydration in newborn infants: retrospective evaluation of 64 cases. The Journal of Maternal-Fetal \& Neonatal Medicine. 2007; 20 (6): 449-52. 10.1080/14767050701398256

14. American Academy of Pediatrics SB, Pediatrics AAo. Breastfeeding and the use of human milk: Am Acad Pediatrics, 2005.

15. Boskabadi $\mathrm{H}$, et al. Significant neonatal weight loss related to idiopathic neonatal hyperbilirubinemia. International Journal of Pediatrics. 2014; 2 (4.1): 225-31. 10.22038/ ijp.2014.3168

16. Behrman R, et al. Behrman: Nelson Textbook of Pediatrics. Philadelphia, Pa: WB Saunders; 2004.

17. Abdelaziz E, Petrik N. hypernatremic dehydration in infancy. Sudanese Journal of Paediatrics 2007;8:161- 70.

18. Moritz ML, et al. Breastfeeding-associated hypernatremia: are we missing the diagnosis? Pediatrics. 2005;116(3):e343-e7.

19. Bermick J, et al. Does hyperglycemia in hypernatremic preterm infants increase the risk of intraventricular hemorrhage[quest]. J Perinatol. 2016;36(9):729-32. 10.1038/jp.2016.86

20. Adrogué HJ, Madias NE. Hypernatremia. New England Journal of Medicine. 2000; 342 (20): 1493-9. doi.10.1056/ NEJM200005183422006

21. Koh T, et al. Neural dysfunction during hypoglycaemia. Archives of disease in childhood. 1988;63(11):1353-8.

22. Moritz ML, Ayus JC. Hyperglycemia Associated with Hypernatremia in Non-diabetic Patients. 1675. Pediatric Research. 1997; 41: 282 